\title{
Individual differences in perceived similarity and preference for visual art: A multidimensional scaling analysis
}

\author{
DAVID O'HARE \\ University of Exeter, Exeter EX4 4QG, England
}

\begin{abstract}
Previous studies have shown that individuals may attend to different dimensions in making an overall judgment of similarity between complex stimuli. The present study investigated the nature of differences in the perceived similarity of reproductions of paintings by the use of multidimensional scaling techniques. Using the INDSCAL model, a group of art-trained students are shown to differ significantly from a group of nonart students in terms of their differential weighing of a set of common dimensions. The same subjects' preferences are examined in relation to these differences by use of the PREFMAP hierarchy of models. While the simplest (vector) model was found to be appropriate for almost all subjects, large differences in vector direction and average subject idealpoint location are found. Implications for future studies of responses to art are discussed.
\end{abstract}

In view of the advantages offered for experimental control and manipulation, it is not surprising that the predominant approach in experimental aesthetics has been through the study of simplified nonrepresentational forms. Implicit in this approach is the view that there is some essential continuity between responses to simple lines and shapes and responses to real works of art. However, since Zusne (1970), in reviewing much of the work on the aesthetics of simple forms, has concluded that "the significant thing about these studies is the low correlation between aesthetic response and the parameters of form"' (Zusne, 1970, p. 396), it seems fairly clear that the study of simple analogs will tell us relatively little about the factors that actually influence responses to works of art.

Studies that have investigated responses to real works of art have often been concerned with such topics as: establishing links between art preference and personality (e.g., Rosenbluh, Owens, \& Pohler, 1972), looking at the relationship between lateral organization and aesthetic preference (e.g., Swartz \& Hewitt, 1970), establishing links between aesthetic judgment and personality (e.g., Child, 1965; Machotka, 1970), or modifying aesthetic preferences experimentally (e.g., Eisenmann \& Boss, 1970; Chapman \& Williams, 1976). By comparison with this work on preference, relatively little has been done on other aspects of aesthetic responding. In particular, Steck and Machotka (1975) note that there is a need for "research on the perception of aesthetic objects to receive the emphasis that has been given to aesthetic preference" (p. 174). The

The author wishes to thank Ian Gordon for invaluable help and advice, and Carolyn Hicks for helping to run the experiment. recent development of multidimensional scaling pioneered by Kruskal (1964) and Shepard (1962) and later developed and extended by a number of others (see Shepard, 1972) has provided the researcher with a range of sophisticated measurement techniques to apply to data obtained from both preference and similarity judgments.

\section{Multidimensional Scaling}

While only requiring simple nonverbal judgments of perceived similarity or preference for a group of objects, multidimensional scaling analyses can be used to determine the dimensions along which a set of stimuli are perceived to vary. The basic model has been extended to include individual differences (Carroll \& Chang, 1970) and to deal with dominance or preference data (see Carroll, 1972). Although these methods have been used in investigating the dimensions of perception of a wide variety of stimuli, including colors (Helm \& Tucker, 1962), geometric forms (Silver, Landis, \& Messick, 1966), taste of nutrients (Schiffman \& Dackis, 1975), complex sounds (Howard \& Silverman, 1976), adjectives (Bush, 1973), psychological concepts (Wainer \& Kaye, 1974), and personal relationships (Jones \& Young, 1972; Mueller, 1974), there have been very few attempts at scaling responses to visual art. Child's (1972) recent review of aesthetics contains only three references to such studies in a bibliography of 150 items. Several of the above studies have indicated that subjects may attend selectively to different dimensions in arriving at an overall judgment of similarity between stimuli (e.g., Landis, Silver, Jones, \& Messick, 1967), and that these differences may be related to other individual characteristics (e.g., Wish, Deutsch, \& Biener, 1970). 
Recently, Berlyne (1975) and Berlyne and Ogilvie (1974) have reported the results of a variety of multidimensional scaling analyses of similarity judgments, preference judgments, and responses to verbal scales obtained from small groups of subjects at the University of Toronto. Using a wide range of reproductions of Western and non-Western paintings, they report that (1) subjects can easily make the kind of judgments required, (2) intersubject consistency is sufficient to use mean scores, (3) similarity judgments can be represented in a three-dimensional space, whose first dimension may be interpreted as degree of realistic representation, (4) similarity and preference judgments are governed by the same attributes of paintings, (5) subjects differing in "level of sophistication" in art did not differ in terms of the dimensions underlying their similarity judgments. This last finding is perhaps surprising in view of Child's (1965) finding that aesthetic judgment is very highly correlated with previous experience of art.

In the present study, we have tried to confirm and extend those basic findings by applying multidimensional scaling techniques to similarity and preference judgments for a sample of Western landscape paintings, obtained from groups of students with differing degrees of training and previous experience of visual art. In particular, the study is designed to answer the following questions: (1) To what does a person respond in a work of art? (i.e., what attributes of pictures are most important in influencing judgments of similarity and preference?) (2) Do people with different degrees of training in visual art attend to different aspects of the same paintings? (i.e., are there differences in the salience of particular dimensions between artistically "sophisticated" and "nonsophisticated" students?) (3) In what way do preferences differ, taking into account any underlying differences in dimension salience between art-trained and nonart students? (4) Do the attributes which govern perceived similarity also influence judgments of preference?

Brief descriptions of the multidimensional scaling methods we have utilized will now be provided. For a more detailed summary of these and other methods, the reader is referred to Green and Carmone (1970) and Green and Rao (1972).

The INDSCAL Model. INDSCAL is a method developed by Carroll and Chang (1970) for carrying out three-way multidimensional scaling (see Carroll $\&$ Wish, 1974). Instead of dealing with a single matrix of data representing the averaged judgments of a group of subjects, INDSCAL performs a metric multidimensional scaling analysis using a separate matrix of judgments for each individual in the group. The model assumes that there are a number of dimensions underlying the perception of the stimuli, which are common to all individuals. Similarity judgments are first converted to scalar products. These are then decomposed into two different matrices. The first show the coordinates of the stimulus points in a space of prespecified dimensionality. This is displayed graphically as the "group space." Distances between points in this space are represented by a weighted Euclidean distance function. These reflect the fact that different dimensions will have differential importance or salience for each subject. In the case where a subject ignores a dimension completely, the corresponding weight would be zero. The program computes these weights and also outputs a subject space which shows each individual subject's weightings of the dimensions of the stimulus space. Thus, although a certain degree of communality is assumed between subjects, a fair degree of freedom is allowed to differentially stretch the configuration according to the idiosyncratic perceptual bias of the individual subject. An important property of the INDSCAL solution is that it is dimensionally unique and therefore cannot be transformed in any way. This obviates the need for complicated rotations, and it is claimed that the INDSCAL dimensions should correspond to fundamental perceptual processes (Carroll \& Wish, 1974).

The PREFMAP model. PREFMAP is a computer program, also developed by J. D. Carroll (see Carroll, 1972) for the analysis of preference data through a hierarchy of models of decreasing complexity. The model assumes a previously established stimulus space (obtained, for example, by applying the INDSCAL model to the same subject's similarity judgments) in which each subject's preference ordering can be represented as an ideal-point (Coombs, 1964). The ideal point is a hypothetical maximally preferred stimulus. The nearer each real stimulus is to the ideal point, the greater is the degree of preference for it. The differences between the models depend on the way in which this distance is calculated. In the most general model (Phase I), this allows each individual to rotate and differentially stretch the dimensions of the space. Phase II allows the differential weighting of dimensions only, while Phase III corresponds to the simple ideal point model in which all subjects share the same joint space. In the simplest model (Phase IV), each subject's preferences are represented as a vector, so that stimulus projections on the vector are maximally correlated with the preference data. To enable the most appropriate model to be chosen, multiple correlations are calculated for each subject with regard to each model. In addition, $F$ ratios are calculated between each pair of models so that the statistical significance of a more complex model in accounting for variance in the data can be assessed. PREFMAP can thus be seen as a multidimensional extension of Coomb's unfolding model (Coombs, 1964). 


\section{METHOD}

Subjects

The first group consisted of 16 first-year undergraduate students studying psychology at the University of Exeter. These will be referred to as the nonart group. The second group comprised 19 first-year students at the Exeter College of Art and will be referred to as the art-trained group. Median ages for the two groups were 19 years and 20 years, respectively. All subjects had studied to " $A$ " level standard. In the case of the College of Art subjects, this meant that they had studied art full-time for at least 3 years. Only one of the undergraduate group had previously studied art.

\begin{abstract}
Materials
Twelve commercially available $35-\mathrm{mm}$ color transparencies of landscape paintings were used. These were the same as those used in a previous experiment (O'Hare \& Gordon, 1976b) and are listed in Table 1. Landscapes were chosen in order to minimize the influence of content on judgments, and were selected in order to cover as wide a range of artistic styles as possible.
\end{abstract}

\section{Apparatus}

Two Kodak Carousel S-AV projectors were used to project the stimuli onto a large screen $2 \mathrm{~m}$ in front of the nearest subject. The size of each image was approximately $1 \times 1.3 \mathrm{~m}$.

\section{Progedure}

Subjects were run in two separate groups. Every subject was asked to complete a short questionnaire, which was designed to obtain a few relevant items of information concerning degree of interest in art, details of formal instruction and examinations taken in art, frequency of visits to art galleries, etc. In order to familiarize the subjects with the paintings to be used in the next part of the experiment, each slide was projected for $1 \mathrm{~min}$ and the subjects were invited to identify the name of the artist who painted it. After each slide had been presented in this way, subjects were asked to make judgments of the degree of similarity of every pair of the pictures they had just seen. It was stressed that this should be based on whatever characteristics the subject thought relevant. These were entered in a booklet, containing a 7-point scale ranging from 1 (extremely similar) to 7 (extremely dissimilar) for each of the 66 pairs. In addition, 6 of the pairs were randomly selected for repeated presentation so that individual subjects rating reliability could be calculated. Each pair was projected for $10 \mathrm{sec}$. The order of presentation of the pairs was based on an optimum order developed by Ross (1934). After completing this, subjects were given a short break before starting on the final part of the experiment. The subjects were asked simply to rank the pictures they had just seen in order of preference. As a help to the memory, each subject was provided with a composite black and white photograph of all 12 paintings.

\section{RESULTS}

\section{Analysis of Similarity Judgments}

Reliability. Spearman's rank correlation coefficients for the six repeated pairs were calculated for each subject. In order to reduce the amount of error in the multidimensional scaling solution as much as possible, subjects who failed to reach a satisfactory level of reliability were eliminated from further analyses. Sixteen subjects failed to reach the criterion (rho $=0.7)$, and their judgments were not used. The analyses to be reported are therefore based on a total of 19 subjects ( 9 art-trained students; 10 nonart students). The mean value of rho for these subjects was 0.85 .
Table 1

Paintings Used as Stimuli

\begin{tabular}{|c|c|}
\hline Artist & Title \\
\hline 1. Canaletto (1697-1768) & Eton College \\
\hline 2. Claude (1600-1682) & $\begin{array}{l}\text { Landscape: The Marriage of } \\
\text { Isaac and Rebekah }\end{array}$ \\
\hline 3. Constable (1776-1837) & Flatford Mill \\
\hline 4. Hunt (1827-1910) & Our English Coasts \\
\hline S. Kokoschka (b. 1886) & Polperro, Cornwall \\
\hline 6. Lowry (1887-1976) & Hillside in Wales \\
\hline 7. Matisse $(1869-1954)$ & Tree near Trivaux Pond \\
\hline 8. Nash (1889-1946) & Landscape from a Dream \\
\hline 9. Rousseau (1844-1910) & The Waterfall \\
\hline 10. Stael, de (1914-1955) & Study at La Ciotat \\
\hline 11. Turner (1775-1851) & $\begin{array}{l}\text { Petworth Park: Tillington } \\
\text { Church in the Distance }\end{array}$ \\
\hline 12. Vlaminck (1876-1958) & Provencal Landscape \\
\hline
\end{tabular}

Table 2

INDSCAL Analysis of Similarity Judgments: Summary Statistics

\begin{tabular}{lrrrr}
\hline \multicolumn{1}{c}{ Statistic } & 4D & \multicolumn{1}{c}{ 3D } & \multicolumn{1}{c}{ 2D } & 1D \\
\hline Percentage variance accounted for & 65.7 & 61.0 & 55.8 & 47.7 \\
Average correlation across subjects & .81 & .78 & .74 & .67 \\
Correlation between data and & & & \multicolumn{1}{c}{.} & \\
similarities & .81 & .78 & .75 & .69 \\
\hline
\end{tabular}

Scaling. A matrix of each subject's judgments of the 66 pairs of stimuli was entered into the INDSCAL programme. In the case of repeated pairs, the first value given was recorded in the matrix. Solutions were computed in four, three, two, and one dimensions. Summary statistics are shown in Table 2. Decisions as to the appropriate dimensionality cannot be made from these statistics alone, and must involve the criteria of interpretability. Pilot work suggested that at most, three dimensions could be interpreted. Initially, then, the three-dimensional solution was selected. Inspection of the subject space, however, showed that differences between the two groups were confined to the first two dimensions. Discussion of individual differences will, therefore, be confined to these two dimensions. The nature and extent of these differences can be seen in Figure 1, which shows the distribution of subjects in the INDSCAL subject space. The art-trained students are characterized by higher weights on Dimension II and lower weights on Dimension I than the nonart students. In terms of variance accounted for by the two dimensions, these show a mean of $34.2 \%(\mathrm{SD}=14 \%)$ for the art students on Dimension I compared with $56.9 \%$ (SD $=18.9 \%$ ) for the nonart students. The differences on Dimension II are $11.53 \%(\mathrm{SD}=2.41 \%)$ and $4.96 \%(\mathrm{SD}=$ $6.74 \%$ ), respectively. A conventional $t$ test shows both these differences to be highly significant, $[\mathrm{t}(17)=3.0, \mathrm{p}<.01$ in the first case and $\mathrm{t}(17)=2.9$, $\mathrm{p}<.01$ in the second]. However, as Coxon and Jones (1974) point out, differences in the amount of variance accounted for in a subject's data by the INDSCAL model will pull apart subjects who, in 
$\operatorname{dim} 2$

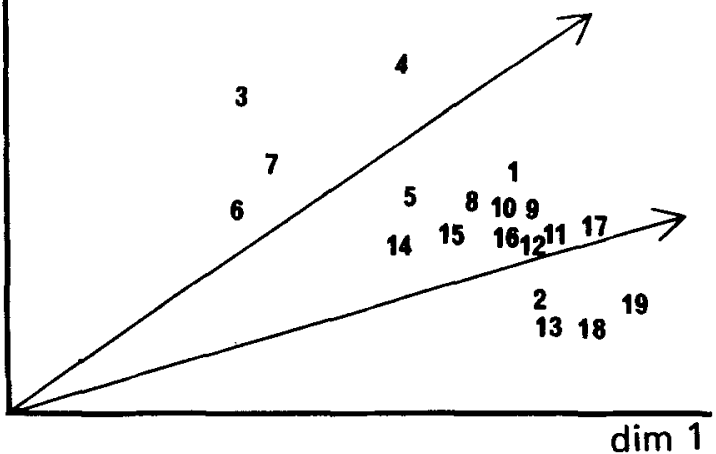

Figure 1. INDSCAL subject space showing individual weights on first two stimulus dimensions. The subjects are numbered as in Table 4.

fact, attach equal relative importance to the dimensions. For this reason, linear statistics or cluster analyses may give misleading results. Individual or group differences are best considered in terms of angular separation, as described below (see also Mardia, 1972.)

Differences between groups. The subject space can be described in terms of mean angular direction and circular variance. These give a mean direction for the art students of $34^{\circ} 5^{\prime}$ and for the nonart students of $16^{\circ} 24^{\prime}$. These are shown in Figure 1 as the upper and lower arrows, respectively. The circular variance indicates the degree of clustering about the mean direction, the nearer the value to zero, the tighter the clustering. The values for the art and nonart groups are 0.081 and 0.004 , respectively. These indicate a considerable degree of clustering for the nonart group; somewhat less so for the art group. To see if the differences between the two groups are significant, we use the uniform-scores test as described by Mardia (1972). Since the nature of the population distribution is uncertain, we have chosen this nonparametric test to examine the null hypothesis that the two samples are drawn from the same population. The test yields a statistic $R_{1}^{2}$, which in the present analysis is computed to be 17.73 . The $5 \%$ value of $R_{1}^{2}$ is 14.58 , and so we reject the null hypothesis. It is clear, therefore, that there are significant differences between the art-trained and the nonart subjects in the relative weighing of the stimulus dimensions. The nature of these differences can be clearly seen by examining the individual stimulus spaces of the two extreme subjects from Figure 1 . These are shown in Figure 2 (art-trained subject) and Figure 3 (nonart subject). These figures show the group stimulus solution differentially stretched according to each subject's idiosyncratic weighting of the dimensions. For the nonart subject (Figure 3), this makes the variation virtually unidimensional, with Dimension II accounting for very little of the variance in his judgments. In contrast, the configuration of the art-trained subject (Figure 2) shows almost equal variation about both axes. Since the INDSCAL program also gives individual goodnessof-fit measures, it is possible to compare the two groups in terms of how well the model accounts for their data. The mean correlations between computed scores and original data are $r=0.83$

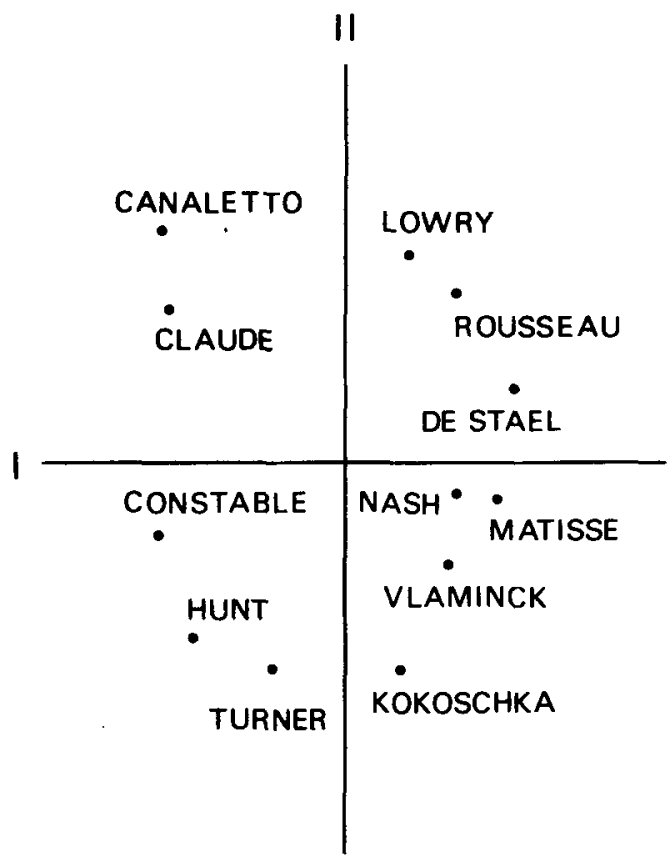

Figure 2. Individual stimulus space (art-trained Subject 3) showing group space differentially stretched according to individual subject's weightings.

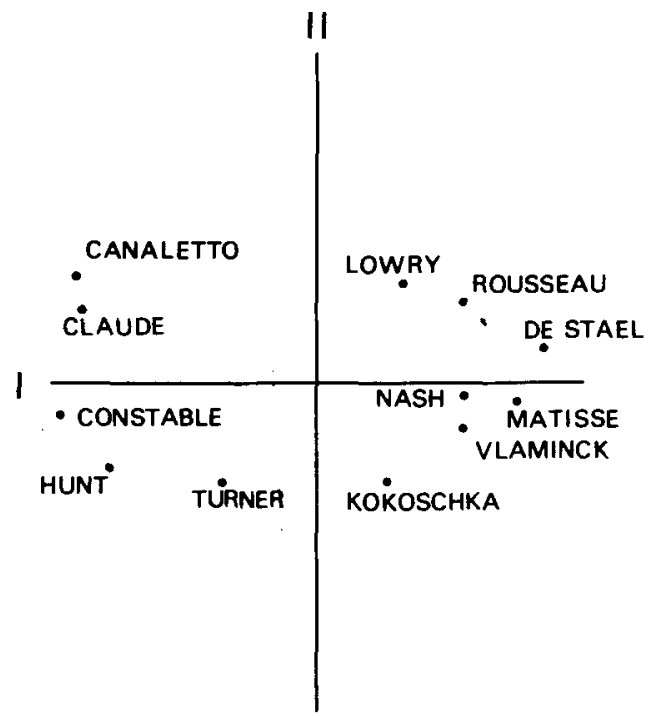

Figure 3. Individual stimulus space (nonart Subject 19). 


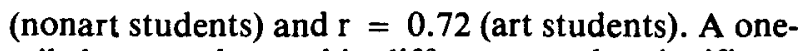
tailed $\mathrm{t}$ test shows this difference to be significant $[t(17)=2.64, p<.01)]$, suggesting that the art students are more likely to be making use of additional idiosyncratic dimensions.

Interpretation of the dimensions. Inspection of the first two dimensions suggests that Dimension I contrasts the representational pictures (Claude, Canaletto, Constable, Hunt, and Turner) with increasingly nonrepresentational pictures (Matisse, de Stael), while Dimension II contrasts the clarity and sharp outlines of Canaletto and Lowry with the more diffuse and indefinite paintings by Turner and Kokoschka. In addition, ratings of the 12 pictures on a set of semantic-differential scales had been obtained previously from a group of 47 undergraduate students. The scales represented commonly occurring constructs elicited from another group of undergraduate subjects in a previous study (O'Hare \& Gordon, 1976a). Product-moment and multiple correlations between the mean values of each picture on each scale and the three INDSCAL dimensions are shown in Table 3. Clearly, the first INDSCAL dimension is almost colinear with the RealisticUnrealistic scale, while the second INDSCAL dimension is significantly related to both the ClearIndefinite and Symmetrical-Asymmetrical scales. Only the Realistic-Unrealistic and Clear-Indefinite scales have significant multiple correlations with the three dimensions collectively. Finally, productmoment correlations between (a) the interpoint distances of the average art-trained subject's configuration, (b) average nonart subject's configuration, with a previously obtained configuration (O'Hare \& Gordon, 1976b) were calculated. These were found to be $r=0.90(\mathrm{df}=64, \mathrm{p}<.001)$ and $r=0.87(\mathrm{df}=64, \mathrm{p}<.001)$, respectively, confirming that the solution obtained in the present experiment is almost exactly the same (except for a permissible reflection of the first axis) as that obtained with a previous group of subjects. In that case, the first two dimensions were also clearly associated with the Realistic-Unrealistic and Clear-Indefinite scales.

\section{Analysis of Preference Judgments}

Inspection of the individual rank orderings suggests that there is little agreement between the art-trained and nonart students with respect to their preferences. The art-trained group show a strong preference for the paintings by Matisse and Vlaminck, whereas the nonart group prefer those by Hunt and Constable. The paintings by Rousseau and Constable were the only two to be ranked highly by both groups. A rank-order correlation coefficient was calculated between the average rankings of the two groups. The obtained value of rho $=0.16$ indicates almost complete absence of agreement. The individual rank
Table 3

Product-Moment and Multiple Correlations Between Scales and INDSCAL Dimensions

\begin{tabular}{|c|c|c|c|c|}
\hline Scale & I & II & III & $\begin{array}{c}\text { Multiple } \\
\text { Corre- } \\
\text { lation }\end{array}$ \\
\hline Simple-Complex & .45 & .20 & -.42 & .66 \\
\hline Active-Static & $.61^{*}$ & .12 & -.20 & .67 \\
\hline Dark Color-Bright Color & $.63^{*}$ & .14 & .23 & .68 \\
\hline Realistic-Unrealistic & $-.94 * *$ & -.04 & -.03 & $.95 * *$ \\
\hline Like-Dislike & $.70^{*}$ & -.08 & -.37 & .82 \\
\hline Clear-Indefinite & $-.64^{*}$ & $.66^{*}$ & -.20 & $.92 * *$ \\
\hline Interesting-Uninteresting & $-.60^{*}$ & -.04 & .41 & .75 \\
\hline Soft/Curved-Angular/Sharp & $.65^{*}$ & .41 & -.15 & .79 \\
\hline Few Colors-Many Colors & -.45 & -.28 & .16 & .56 \\
\hline Symmetrical-Asymmetrical & -.23 & $-.66^{*}$ & .00 & .70 \\
\hline Peaceful-Disturbed & $.63^{*}$ & -.38 & -.14 & .77 \\
\hline$(x)=10$ & & & 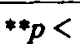 & \\
\hline
\end{tabular}

orderings were then analyzed separately for the two groups using the metric version of the PREFMAP program. The input for this analysis consists of the coordinates of the stimuli in the average subject's similarity space plus the rank orderings in terms of preference, for each individual in the group. Comparing, first, Phase I with Phase II shows that there is little to be gained by using the more complex model. The root mean squares of the individual goodness-of-fit measures for the two groups are 0.978 and 0.963 for Phase $I$, dropping only to 0.922 and 0.851 , respectively, for Phase II. Inspection of the between-phase F ratios (see Table 4) shows that Phase I provides a significantly better fit in the case of only one subject. Similarly, a comparison of Phase II with Phase III shows that in no case does the $F$ value exceed the value required for significance $(13.27 ; \mathrm{df}=2,5)$. This suggests that the preference data for almost every subject could be fitted by either the ideal-point model (Phase III) or the simple vector model (Phase IV).

\section{Comparison of Ideal-Point and Vector Models}

A separate analysis was performed comparing only Phase III with Phase IV of the PREFMAP program. Again, referring to Table 4, in the case of only 1 subject does the ideal-point model provide a significantly better fit than the vector model. The remaining 17 subjects can therefore be compared in terms of vector direction in the average subject's similarity space for the group. Figures 4 and 5 show the preference vectors and ideal-point location for each subject in the two groups. The position of the average subject's ideal point is also indicated.

\section{DISCUSSION}

The first point to emerge is that the pairedcomparison method of collecting similarity judgments used in the present experiment is subject to 
Table 4

Between-Phase F Ratios for Multidimensional Preference Analysis of Art-Trained and Nonart Groups

F Ratio Between Phases

\begin{tabular}{|c|c|c|c|}
\hline Group & $\begin{array}{c}\text { I and II } \\
(\mathrm{df}=3 / 2)\end{array}$ & $\begin{array}{l}\text { II and III } \\
(\mathrm{df}=2 / 5)\end{array}$ & $\begin{array}{l}\text { III and IV } \\
(\mathrm{df}=1 / 7)\end{array}$ \\
\hline & \multicolumn{3}{|c|}{ Art-Trained } \\
\hline 1 & 12.76 & 6.28 & $14.00^{*}$ \\
\hline 2 & .86 & .10 & .10 \\
\hline 3 & 2.99 & 3.56 & 2.51 \\
\hline 4 & 5.86 & 1.55 & .16 \\
\hline 5 & .22 & .40 & .15 \\
\hline 6 & .31 & 3.91 & .01 \\
\hline 7 & 8.66 & 1.12 & .35 \\
\hline 8 & .56 & .49 & .16 \\
\hline \multirow[t]{2}{*}{9} & .33 & 2.33 & .47 \\
\hline & \multicolumn{3}{|c|}{ Nonart } \\
\hline 10 & 14.79 & 2.89 & 1.33 \\
\hline 11 & .58 & .21 & .17 \\
\hline 12 & 1.48 & .44 & 1.33 \\
\hline 13 & 4.35 & .66 & .62 \\
\hline 14 & 2.33 & .70 & .24 \\
\hline 15 & $1000.00^{*}$ & .58 & .18 \\
\hline 16 & 8.87 & 3.29 & 3.62 \\
\hline 17 & .12 & 1.87 & .63 \\
\hline 18 & .86 & .37 & .04 \\
\hline 19 & 12.19 & .30 & .03 \\
\hline
\end{tabular}

$* p<.01$

a great deal of unreliability. This has also been reported by Linde (1975). This may be due to a certain amount of respondent fatigue developing during presentation of the later pairs, and it may be the case that some other data collection procedure such as the method of sorting (Rosenberg \& Kim, 1975) would be preferable.

\section{Dimensions of Stimulus Variation}

As Silver et al. (1966) have pointed out in connection with form perception, the question of what the dimensions of the perception of art are cannot be answered by a study such as this, which involves a small sample of pictures from a very large population of art works in general. However, by repeated sampling from the population one can increase confidence in the generality of the results. Presumably with this in mind, Berlyne urges that "this means, in particular, extending this line of research to more and more kinds of stimulus material" (Berlyne, 1975 , p. 152). Comparing the results of the present experiment with previous attempts to identify salient dimensions involved in the perception of visual art suggests some consistency across different studies involving different samples of paintings. Several studies (Berlyne \& Ogilvie, 1974; Klein, 1968; O'Hare \& Gordon, 1976b; Ruth \& Kolehmainen, 1974) report degree of realism to be an important attribute in influencing responses to paintings. In the present case, this was found to be clearly the most important perceptual dimension. The second dimension identified in the present study-clarity, or clear definition of detail-has also been reported in a number of studies (Berlyne, 1973; Klein, 1968; O'Hare \& Gordon, 1976b; Skager et al., 1968). This suggests that, although there may well be other attributes which influence perceived similarity between paintings, degree of realism and clarity of detail may be generally important dimensions of variation. In addition, since the ability to discriminate between works by different artists (and conversely, to recognize several works as being the product of a

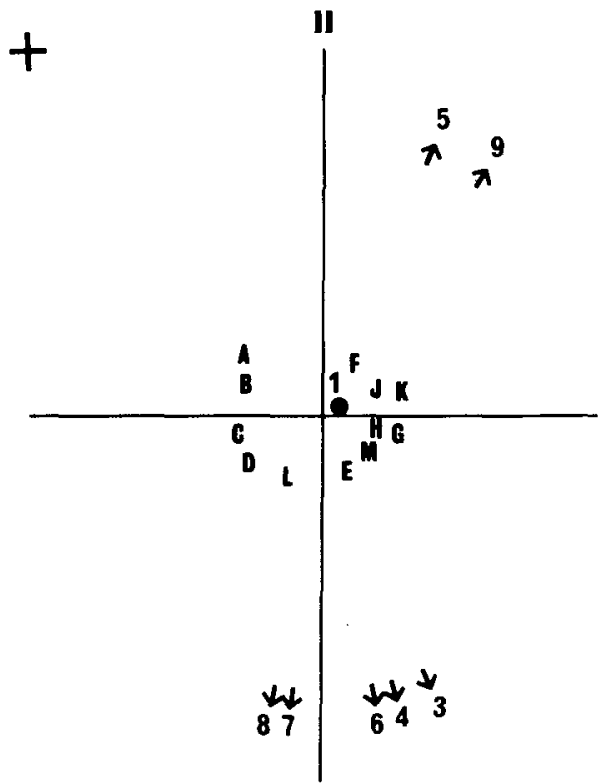

Figure 4. Joint-space configuration of art-trained subjects. Arrows indicate individual preference vectors, while circles represent ideal points. Numbers refer to Table 4 . The position of the average subject's ideal point is indicated by a cross.

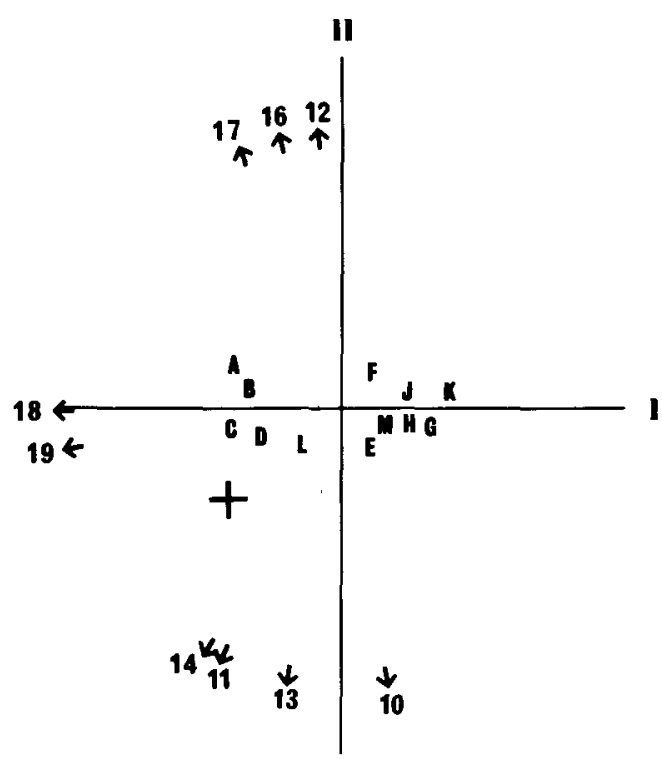

Figure 5. Joint-space configuration of nonart subjects. 
single artist) must necessarily involve the recognition of similarity or dissimilarity (Gardner, 1972; Silverman, Winner, Rosenstiel, \& Gardner, 1975), the dimensions identified through the multidimensional scaling analysis of similarity judgments may function as central attributes of style detection.

\section{Individual Differences}

Subjects with some training in visual art clearly differ from subjects without such training. This difference can be characterized in two ways, firstly, in terms of differential salience of a set of common underlying dimensions. Thus art students attach relatively less importance to degree of realism, and relatively more importance to the clarity of detail portrayed, than do the nonart students. Second, the lower overall fit of the INDSCAL model to the art students' data suggests that they were using more idiosyncratic dimensions than the nonart students. Although Berlyne and Ogilvie (1974) failed to find a difference between their "sophisticated" and "nonsophisticated" subjects, other studies (e.g., Landis et al., 1967) have found similarity judgments to be related to a subject's degree of training and previous experience. Howard and Silverman (1976), for example, report that individual differences in the salience of the dimensions involved in perceiving complex nonspeech sounds differed according to the previous musical experience of the subject. The extent to which those differences represent genuine "perceptual" differences is difficult to determine. In part, this is a result of a general confusion in the literature where the terms "perception," "cognition," and "similarity" are used almost interchangeably. Isaac (1970) has examined this question of whether similarity judgments and multidimensional configurations are indices of perceptual structure, arguing that this can be demonstrated by showing compatability with other tasks which are also presumed to draw upon the same structure. Isaac concludes that "MDS configurations are indices of a more general perceptual structure, and that differences between S's . . . can be attributed to individual differences in perception" (Isaac, 1970, p. 231). The data presented here clearly do not warrant such a strong assertion, although the demonstrated congruence with other solutions and previously obtained configurations does suggest a degree of generality for the present solution (Stewart, 1974).

\section{Differences in Evaluating Art}

As expected, the art-trained subjects show a clear preference towards the nonrepresentational paintings on Dimension I, with the nonart group displaying a similar preference towards the more traditional works at the opposite end of the dimension. However, most of the vectors are centered about
Dimension II, indicating that, for both groups, it is changes along this dimension that are most important in influencing judgments of preference.

The positionıngs of the average subject's ideal points are of some interest. For the nonart group, its position indicates a maximal attraction to paintings of a representational, but indefinite, nature. The closest to the ideal in the present sample is the work of Turner, but the type of painting that would correspond most closely to this ideal would probably be some Impressionist work. In contrast, the average ideal point of the art-trained group is located at the extremes of Dimensions I and II, corresponding to realism and clarity. The weights associated with the ideal point indicate that it is, in fact, a pessimal (least-preferred) point, indicating that the art-trained students have a maximal aversion from extreme examples of representational-clear pictures, the nearest example in the present case being the work by Canaletto.

\section{Relation Between Similarity and Preference}

Since the stimulus space established by the INDSCAL method needed no modification (either by rotation or differential stretching through the application of PREFMAP Phase I or II) in the context of preference, the finding that the attributes which govern similarity also govern preference (Berlyne \& Ogilvie, 1974) is emphatically supported. However, it is important to note that the relative importance of the dimensions was found to change in the context of preference. While the dimension reflecting the degree of realism was found to be most important in influencing judgments of similarity, the distribution of preference vectors along the second similarity dimension shows that this clear-indefinite dimension becomes more important in influencing judgments of preference.

It is to be hoped that the results reported here will be suggestive of further research. In particular, it seems important to maintain the distinction between perceiving and evaluating art, especially in studies which are designed to alter responses in some way, since it has been shown that responses to art can be manipulated without affecting the subject's perceptual organization of the stimuli (Chapman \& Williams, 1976; O'Hare \& Gordon, 1976a; Stalling \& Tiller, 1975.)

\section{REFERENCES}

Berlyne, D. E. Interrelations of verbal and nonverbal measures used in experimental aesthetics. Scandinavian Journal of Psychology, 1973, 14, 177-184.

BerLyne, D. E. Dimensions of perception of exotic and prerenaissance paintings. Canadian Journal of Psychology, 1975, 29, 151-173.

Berly ne, D. E., \& OgIlvie, J. C. Dimensions of perception of paintings. In D. E. Berlyne (Ed.), Studies in the new experimental aesthetics. Washington: Hemisphere, 1974. 
Bush, L. Individual differences multidimensional scaling of adjectives denoting feelings. Journal of Personality and Social Psychology, 1973, 25, 50-57.

CARRoll, J. D. Individual differences and multidimensional scaling. In R. N. Shepard, A. K. Romney, \& S. B. Nerlove (Eds.), Multidimensional scaling. New York: Seminar Press, 1972.

Carrold, J. D., \& Chang, J. J. Analysis of individual differences in multidimensional scaling via an $\mathrm{N}$-way generalization of Eckart-Young"' decomposition. Psychometrika, 1970, 35, 285-319.

CARRoll, J. D., \& WiSh, M. Models and methods tor three-way multidimensional scaling. In D. Krantz, R. Atkinson, R. Luce, \& P. Suppes (Eds.), Contemporary developments in mathematical psychology (Vol. II). San Francisco: Freeman, 1974.

Chapman, A. J., \& Williams, A. R. Prestige effects and aesthetic experiences: Adolescents' reactions to music. British Journal of Social and Clinical Psychology, 1976, 15, 61-72.

ChILD, I. L. Personality correlates of aesthetic judgment in college students. Journal of Personality, 1965, 33, 476-511.

CHILd, I. L. Esthetics. Annual Review of Psychology, 1972, 23, 669-694.

Coombs, C. H. A theory of data. New York: Wiley, 1964.

Coxon, A. P. M., \& JoNes, C. L. Occupational similarities: Subjective aspects of social stratification. Quality and Quantity, 1974, 8, 139-157.

Eisenmann, R., \& Boss, E. Complexity-simplicity and persuasibility. Perceptual and Motor Skills, 1970, 31, 651-656.

GARDNER, H. Style sensitivity in children. Human Development, $1972,15,325-338$.

Green, P. E., \& CARMone, R. J. Multidimensional scaling and related techniques in marketing analysis. Boston: Allyn \& Bacon, 1970.

GREEN, P. E., \& RAo, V. R. Applied multidimensional scaling: A comparison of approaches and algorithms. New York: Holt, Rinehart, \& Winston, 1972.

Helm, C. E., \& TUCKER, L. R. Individual differences in the structure of color-perception. American Journal of Psychology, 1962, 75, 437.444

Howard, J. H., \& Silverman, E. B. A multidimensional scaling analysis of 16 complex sounds. Perception \& Psychophysics, $1976,19,193-200$.

IsAAC, P. D. Dissimilarities as indices of individual perceptual structure. Perception \& Psychophysics, 1970, 7, 229-233.

JoNes, L. E., \& Young, F. Structure of a social environment: Longitudinal individual differences scaling of an intact group. Journal of Personality and Social Psychology, 1972, 24, 108-121.

KLEIN, S. P. Using points of view and multidimensional scaling analyses to describe esthetic judgements. Proceedings of the 76th Annual Convention A. P. A., 1968, 447.448.

KrusKaL, J. B. Multidimensional scaling by optimizing goodnessof-fit to a nonmetric hypothesis. Psychometrika, 1964, 29, 1-27.

Landis, D., Silver, C. A., Jones, J. M., \& Messick, S. Level of proficiency and multidimensional viewpoints about problem similarity. Journal of Applied Psychology, 1967, 51, 216-222.

LINDE, L. Similarity of poetic rhythms with different amounts of semantic content-stress ratings and paitwise similarity ratings. Scandinavian Journal of Psychology, 1975, 16, 240-246.

MAсноткA, P. Visual aesthetics and learning. Journal of Aesthetic Education, 1970, 4, 117-130.

Mardia, K. V. Statistics of directional data. London: Academic Press, 1972.
Mueller, W. S. Cognitive complexity and salience of dimensions in person perception. Australian Journal of Psychology, 1974, 26, 173-182.

O'HARE, D. P. A., \& Gordon, I. E. An application of repertory grid technique to aesthetic measurement. Perceptual and Motor Skills, 1976, 42, 1183-1192. (a)

O'HARE, D. P. A., \& Gordon, I. E. Dimensions of the perception of art- verbal scales and similarity judgements. Scandinavian Journal of Psychology, 1976, in press. (b)

RosenberG, S., \& KIM, M. P. The method of sorting as a datagathering procedure in multivariate research. Multivariate Behavioral Research, 1975, 10, 489-502.

Rosenblut, E. S., Owens, G. B., \& Pohler, M. J. Art preference and personality. British Joumal of Psychology, 1972, 63, 441-443.

Ross, R. Optimum orders for the presentation of pairs in the method of paired comparisons. Journal of Educational Psychology, 1934, 25, 375-382.

Ruth, J., \& Kolehmainen, K. Classification of art into style periods: A factor analytic approach. Scandinavian Journal of Psychology, 1974, 15, 322-327.

Schiffman, S., \& Dackis, C. Taste of nutrients: Amino acids, vitamins, and fatty acids. Perception \& Psychophysics, 1975, 17, 140-146.

Shepard, R. N. The analysis of proximities: Multidimensional scaling with an unknown distance function. Psychometrika, $1962,27,125-139$.

SHEPARD, R. N. Introduction. In R. N. Shepard, A. K. Romney, \& S. B. Nerlove (Eds.), Multidimensional scaling. New York: Seminar Press, 1972.

Silver, C. A., Landis, D., \& Messick, S. Multidimensional analysis of visual form: An analysis of individual differences. American Journal of Psychology, 1966, 79, 62-72.

Silverman, J., Winner, E., Rosensteil, A. K., \& Gardner, H. On training sensitivity to painting styles. Perception, 1975, 4, 373-384.

Skager, R. W., Schultz, C., \& K Kein, S. The multidimensional scaling of a set of artistic drawings: Perceived structure and scale correlates. Multivariate Behavioral Research, 1966, 1, 425-436.

Stalling, R. B., \& Tiller, J. Modifying a response class of artistic taste with signal light reinforcers. Psychological Record, 1975, 25, 65-69.

STECK, L., \& MachotKa, P. Preference for musical complexity: Effects of context. Journal of Experimental Psychology, 1975, 104, 170-174.

STEWART, T. R. Generality of multidimensional representations. Multivariate Behavioral Research, 1974, 9, 507-519.

SwarTz, P., \& HewitT, D. Lateral organisation in pictures and aesthetic preference. Perceptual and Motor Skills, 1970, 30, 991-1007.

WAINER, H., \& KAYE, K. Multidimensional scaling of concept learning in an introd uctory course. Journal of Education Psychology, 1974, 66, 591-598.

Wish, M., Deutsch, M., \& Biener, L. Differences in conceptual structures of nations: An exploratory study. Joumal of Personality and Social Psychology, 1970, 16, 361-373.

Zusne, L. Visual perception of form. London: Academic Press, 1970.
(Received for publication May 24, 1976; revision accepted August 19, 1976.) 